Ryogo Nakada • Yoshitake Fujisawa - Kana Yamashita Yasuhiko Hirakawa

\title{
Changes in water distribution in heartwood along stem axes in Cryptomeria japonica
}

Received: December 21, 2001 / Accepted: May 1, 2002

\begin{abstract}
Three-dimensional distribution of water in the heartwood of Cryptomeria japonica D. Don was observed by soft X-ray photography. The within-tree variation in the distribution of "wet areas" (water-accumulated areas in heartwood) was enormous, as was the variation among trees. Although we found no universal pattern of changes in wet area distributions along the stem axes of all trees, similarities among individual trees within each cultivar and clone were observed. The difference between the two kinds of wetwood in C. japonica - genetically defined wetwood and secondarily induced wetwood - is discussed, as is the use of soft X-ray photography in Japanese tree breeding programs.
\end{abstract}

Key words Cryptomeria japonica $\cdot$ Wetwood $\cdot$ Soft X-ray photography $\cdot$ Within-tree variation $\cdot$ Heartwood

\section{Introduction}

In our previous studies ${ }^{1,2}$ we used soft $\mathrm{X}$-ray photography to determine the water distribution in the heartwood of living trees of Cryptomeria japonica D. Don. Observations of thin sections of tree stems by soft X-ray photography are useful for detecting the presence and distribution of water in the

R. Nakada $(\square)$

Forest Tree Breeding Center, 3809-1 Ishi, Juo, Ibaraki 319-1301, Japan

Tel. +81-293-32-7045; Fax +81-293-32-7306

e-mail: ryogo@nftbc.affrc.go.jp

Y. Fujisawa

Kyushu Regional Breeding Office, Forest Tree Breeding Center, Nishi-goshi 861-1102, Japan

K. Yamashita $\cdot$ Y. Hirakawa

Forestry and Forest Products Research Institute, Kukizaki 305-8687, Japan

Part of this paper was presented at the 46th Annual Meeting of the Japan Wood Research Society, Kumamoto, Japan, April 1996 sections separately from defects such as knots. The results showed enormous variations in water distribution within and among trees. ${ }^{1,2}$ There is no doubt that the difficulty of drying lumber in this species is a result of both water accumulation in heartwood, which increases the moisture content of the wood, and the large variability in water distribution within and among trees.

The conclusions of those two earlier studies ${ }^{1,2}$ were that (1) water in heartwood was generally maldistributed; (2) there were three types of water presence in heartwood; a wet area, a dry area, and a moderate moisture area; (3) wet areas had two appearances: regularly distributed wet areas and irregularly distributed wet areas; (4) there were five basic wet area distribution patterns (Fig. 1) in the transverse planes of the stems; (5) in the lower portions of the stems, the wet area distribution patterns were distinctively different among clones of the species, but the patterns were similar among individual trees within each clone; and (6) variations of water distribution within stems described by the wet area distribution pattern highly corresponded to the variation in the moisture content of the wood. The five basic types of the wet area distribution pattern (Fig. 1) were as follows: type 1, dry areas or moderate moisture areas were present in the heartwood without a regularly distributed wet area; type 2, the regularly distributed wet area formed a circle around the pith; type 3 , the regularly distributed wet area was doughnut-shaped; type 4, the wet area occupied almost all of the heartwood; type 5, patterns not fitting the above four categories or patterns in which wet areas in the heartwood were mostly distributed irregularly. Intermediate or complex versions of these five basic types were found frequently.

Many researchers have studied the moisture content of C. japonica heartwood, but most of them examined samples obtained from a low height in the stem, mainly at breast height. It has been reported that the moisture content of heartwood in this species varies longitudinally within a stem. ${ }^{3-6}$ Nakada et al. ${ }^{6}$ defined seven changing patterns of the mean moisture content along the stem axis in heartwood. These findings indicate that the wet area distribution in heartwood also changes longitudinally within each stem. 


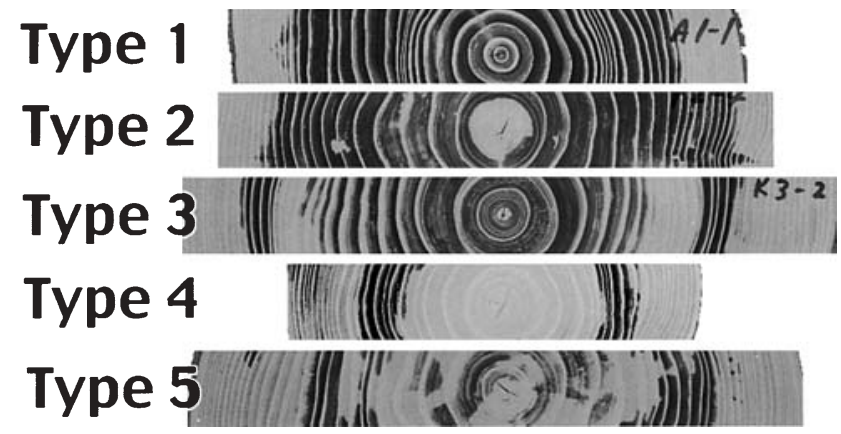

$5 \mathrm{~cm}$

Fig. 1. Soft X-ray photographs of sections representing wet area distributions in heartwood. Type 1: tree A1, a Mito cultivar, aya-sugi, height (h) above ground $0.7 \mathrm{~m}$. Type 2: tree $\mathrm{P} 2$, a Mito cultivar, hon'na-sugi, $\mathrm{h}$ $5.5 \mathrm{~m}$. Type 3: tree K3, a Mito cultivar, kuma-sugi, h $1.5 \mathrm{~m}$. Type 4: tree 41, a Mito clone, yaita 3, h 6.0 m. Type 5: tree F3, a Mito cultivar, toudosugi, h $3.5 \mathrm{~m}$. Note: All figures except Fig. 10 are photographs of transverse sections of stems. All photographs were taken under green conditions. All X-ray photographs in this study were computerprocessed and are represented in photographic negative; that is, darker parts in photographs indicate areas that absorbed fewer X-rays and held little water; the lighter parts demonstrate the opposite

In this article we describe within-tree changes along the stem axes of the wet area distribution in heartwood. We also demonstrate that trees within a clone or cultivar have similar three-dimensional changing patterns of wet area distribution.

\section{Materials and methods}

In total, 95 trees of $C$. japonica were investigated for this study. Three individual trees of a plus tree clone, kaga 3, were collected from the clonal archives at the San-in Branch Office, Kansai Breeding Office, Forest Tree Breeding Center (Chizu, Tottori Prefecture, Japan). In this article, these sample trees from Chizu are called "Chizu trees." Three individual trees were collected from each of 11 plus tree clones, and two trees of another clone were collected from the clonal archives at the Forest Tree Breeding Center (Mito, Ibaraki Prefecture, Japan). The trees of the plus tree clones from Mito are called "Mito clones." The sample trees of the Mito clones were the same individuals we used as samples in our previous report. ${ }^{1}$ Three individual trees from each of 19 cultivars were collected from the archives of sugi cultivars at the Forest Tree Breeding Center. They were named "Mito cultivars." The sample trees of the Mito cultivars were the same individuals used in our previous studies. ${ }^{6}$ Table 1 describes the sample trees in detail.

Disks were sawed from the tree stems, and strips including the pith were then made from the disks. The strips were sawed into transverse sections by a circular saw. The section thickness was $2 \mathrm{~mm}$ for Chizu trees and $5 \mathrm{~mm}$ for Mito clones and Mito cultivars. The quantities of sections obtained from each sample tree were as follows: From each Chizu tree, 50-100 pieces were obtained at various inter- vals; from each Mito clone and Mito cultivar, 7 or 8 pieces were obtained at 1- to 2-m intervals. The lowest and uppermost heights from which sections were collected were 0.7 and $16.0 \mathrm{~m}$ above the ground, respectively.

The prepared sections were placed on X-ray film packs (Fuji FR for Chizu trees and Kodak X-OMAT TL readypack for Mito clones and Mito cultivars) directly and were irradiated by three different soft X-ray irradiators for each group of materials (all irradiators were products of Softex). The irradiating conditions are described in Table 2.

The processed films were observed by the naked eye with transparent light. The images were also scanned into a computer system with a flatbed scanner and were then observed on the monitor. All X-ray photographs in this study were computer-processed and are represented in photographic negative; that is, the darker parts of the photographs indicate areas that absorbed fewer X-rays and held little water; and the lighter parts demonstrate the opposite.

\section{Results}

Generally, the two-dimensional patterns of wet area distribution in transverse sections varied among sections, even if they were taken from the same tree. Figures 2-7 show how the wet area distribution varied within each tree. Two wet area distributions were observed: regularly and irregularly distributed wet areas. ${ }^{2}$ Although both were observed anywhere in the stems, the irregularly distributed wet areas tended to appear higher in the stems. The two-dimensional distribution patterns of wet areas were categorized into five basic types (Fig. 1). ${ }^{2}$ All five types appeared at any height in the stems, as did the intermediate or complex versions of the basic types.

These wet area distribution patterns tended to take on certain appearances. Type 2 and its related types [i.e., the basic types and their intermediate or complex versions of the basic types whose wet areas appeared near the pith (i.e., types $^{2} 1 / 2,2 / 3,2 / 4$, and 4)] tended to appear successively along the stem axes. Figure 2 shows that, in all sections collected from one stem, wet areas were found near the pith. There was no tree in which the entire stem was occupied by type 4; that is, there was always a moderate moisture area or dry area somewhere in the heartwood of the stem. In other words, a wet area did not occupy all of the heartwood area. Figure 3 shows a tree that contained one of the largest amounts of wet area in this study. There are moderate moisture areas on sections collected from 4.1, 6.1, and $8.1 \mathrm{~m}$ above the ground. In trees containing small amounts of wet area, the wet area tended to appear in higher portions of the stems (Fig. 4).

No universal pattern was found in the longitudinal change of the wet area distribution along the stem axes. However, individual trees within each clone or cultivar did have similar three-dimensional wet area distributions. Similarities between individual trees were observed in 5 of 12 Mito clones and 8 of 19 Mito cultivars, and the variations between individuals were categorized as "small" (Table 1). 


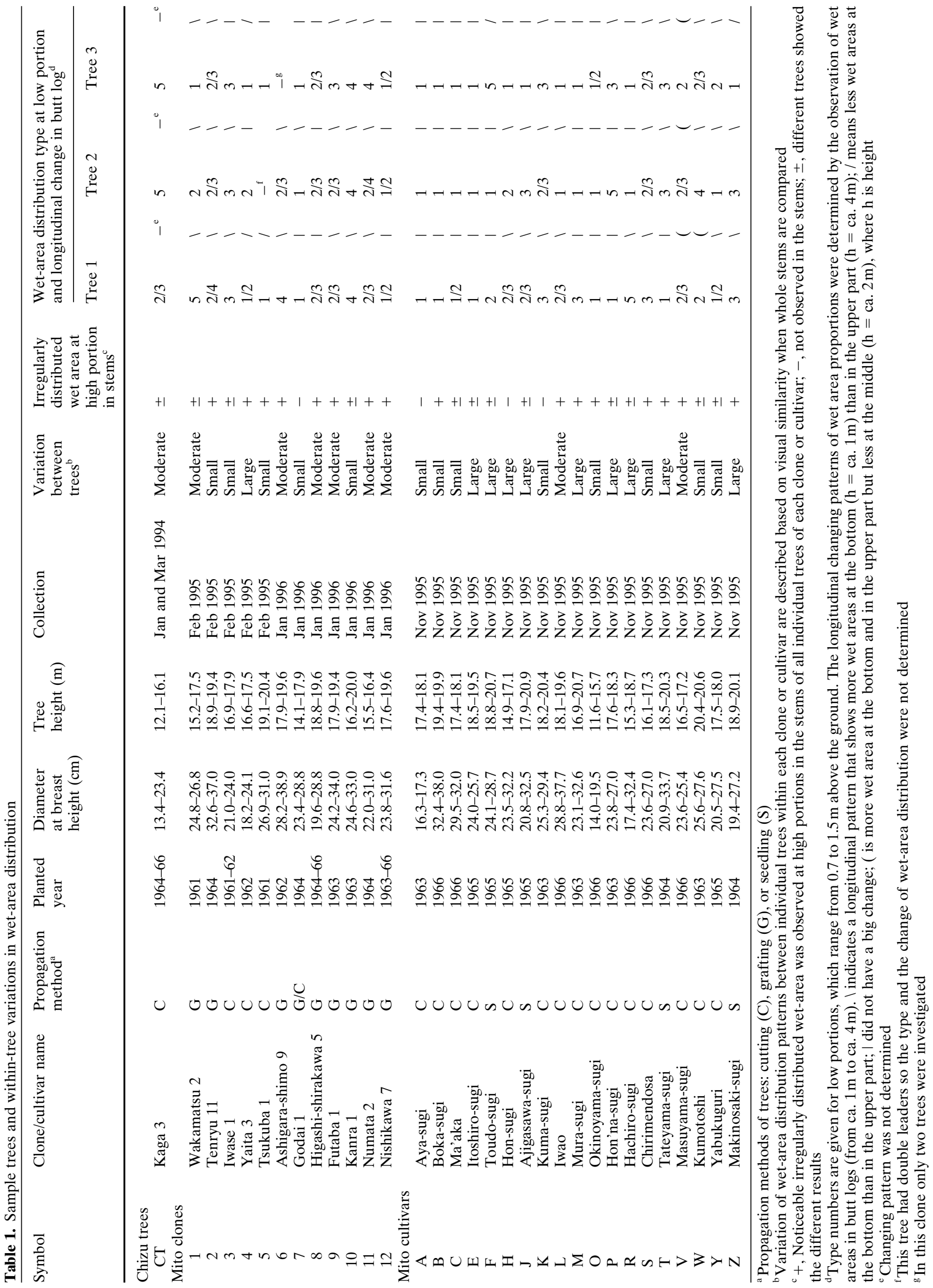


Tabel 2. Soft X-ray irradiation conditions

\begin{tabular}{lllll}
\hline Samples & $\begin{array}{l}\text { Irradiating } \\
\text { time }\end{array}$ & $\begin{array}{l}\text { Voltage } \\
(\mathrm{kVP})\end{array}$ & Current (mA) & $\begin{array}{l}\text { Distance from the } \\
\text { focusing plane }(\mathrm{m})\end{array}$ \\
\hline Chizu trees & $45 \mathrm{~s}$ & 20 & 4 & 0.60 \\
Mito clones & $4.5 \mathrm{~min}$ & 15 & 12 & 1.45 \\
Mito cultivars & $4 \mathrm{~min}$ & 17 & 14 & 2.50 \\
\hline
\end{tabular}

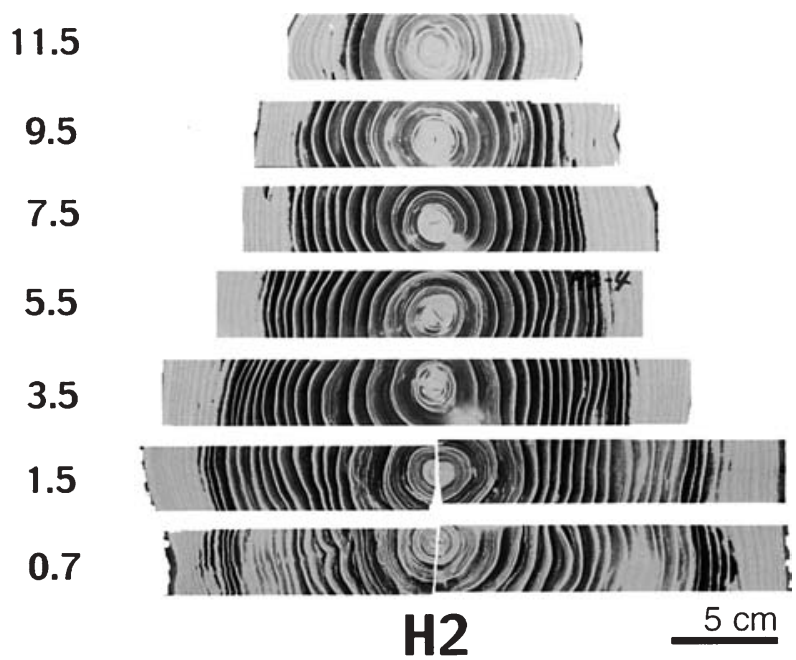

Fig. 2. Soft X-ray photographs of sections collected from various heights of a tree. It shows wet areas near the pith, which were found in all sections. Tree H2, a Mito cultivar, hon-sugi. Note: In Figs. 2-8, the numbers beside the sections indicate section heights (meters) in trees above the ground. In Figs. 2-12, letters under the sections indicate tree designations

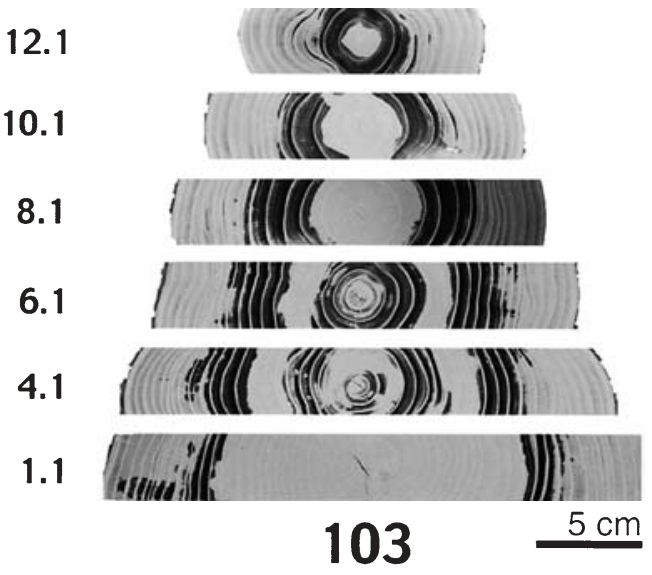

Fig. 3. Soft X-ray photographs of sections collected from various heights of a tree that had the largest amount of the wet area in the stem among investigated trees. Tree 103, a Mito clone, kanra 1

In Fig. 5 the wet area accumulated as type 3 at the bottom $(1.0 \mathrm{~m})$ and then changed to type $4(10.0 \mathrm{~m})$ through the middle portions $(4.0 \mathrm{~m})$ of less-wet areas in all three individuals of the clone. In some clones and cultivars, however, the wet area distribution differed among individual trees, and the variations among individuals are categorized as "large" in Table 1. For example, three individuals of clone 1 (Fig. 6) were different from each other in terms of water

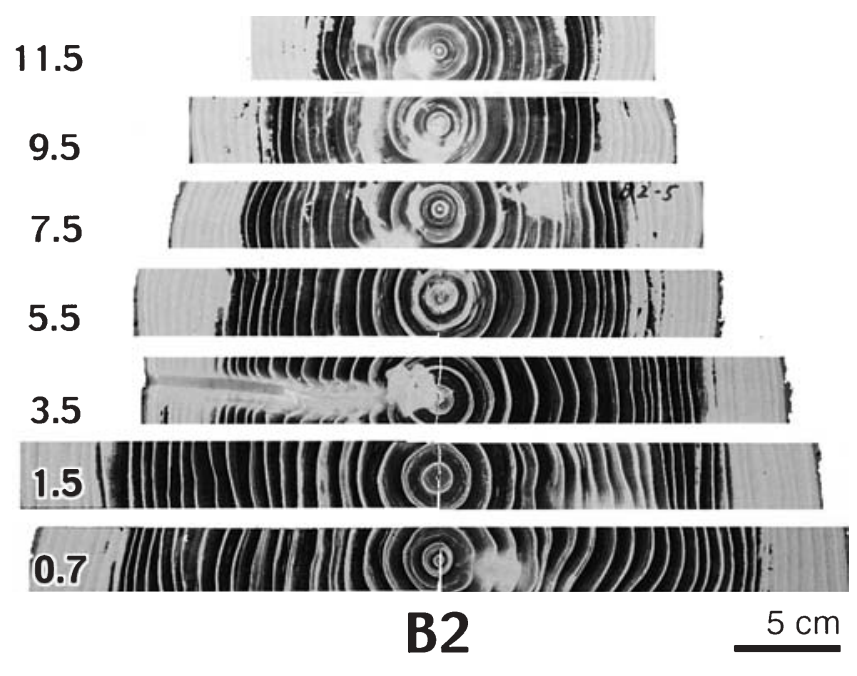

Fig. 4. Soft X-ray photographs of sections collected from various heights of a tree that had a small amount of wet area, showing that the wet area tended to appear in high portions in the stem. Tree B2, a Mito cultivar, boka-sugi

distribution. All sections from tree 11 contained irregularly distributed wet areas, and sections taken at 1, 6, and $12 \mathrm{~m}$ above the ground were typical for type 5 . The low portion $(1 \mathrm{~m})$ of tree 12 was categorized as type 2; the upper stem (12 and $14 \mathrm{~m}$ ) did not have wet areas, whereas the middle portion $(4,6$, and $8 \mathrm{~m})$ contained developed irregularly wet areas. Tree 13 had only small irregularly distributed wet areas in some sections. The variation in the water distribution among individuals in clone 1 was much larger than that in the clones (e.g., clone 3 in Fig. 5), revealing a "small" variation among individuals. Categorization of the similarity of individuals within each clone and cultivar was determined by: (1) comparing the types of water distribution at each height of the section; and then (2) a visual subjective impression when the photographs of all sections of individuals were gathered.

Figure 7 shows three trees of a clone that has one of the smallest amounts of wet area among all of the clones and cultivars in this study. Tree 72 had been damaged seriously by attacks of sugi bark borers (Semanotus japonicus). The arrows in tree 72 indicate decayed zones caused by these attacks. Tree 73 had double leaders at $8.25 \mathrm{~m}$ above the ground. The heights just underneath or above the branching of the leaders (sections $\mathrm{O}, \mathrm{P}$, and $\mathrm{Q}$ ) had relatively small wet areas.

All individual trees of a cultivar (aya-sugi) and a plus tree clone (godai 1) (Fig. 7) had little wet area throughout their stems. One tree each of cultivars hon-sugi, honna-sugi, 
Fig. 5. Soft X-ray photographs of sections collected from various heights of three trees of a clone, showing similarities in wet area distribution between trees. Trees 31, 32, and 33, a Mito clone, iwase 1

Fig. 6. Soft X-ray photographs of sections collected from various heights of three trees of a clone, showing differences in wet area distribution among trees. Trees 11, 12, and 13, a Mito clone, wakamatsu 2

14.0

12.0

10.0

8.0

6.0

4.0

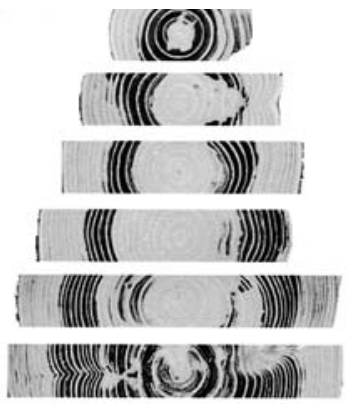

1.0

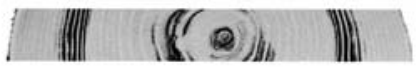

31

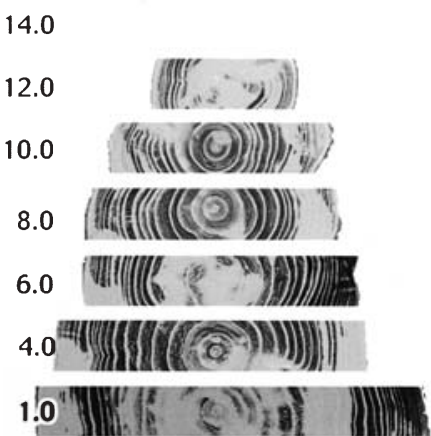

11

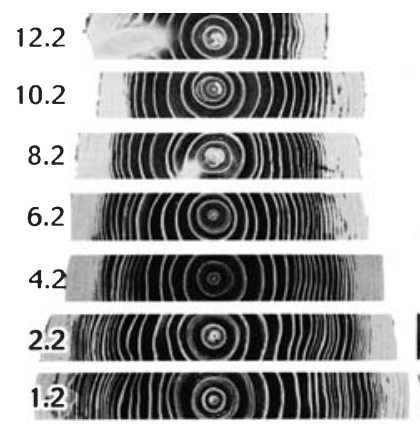

71
Fig. 7. Soft X-ray photographs of sections collected from various heights of three trees of a clone, showing little wet area in the stems. Trees 71, 72, and 73, a Mito clone, godai 1. Arrows in tree 72 indicate decayed areas caused by attacks of sugi bark borers. Sections $\mathrm{P}$ and $\mathrm{Q}$ (h $8.3 \mathrm{~m}$ ) were corrected from double leaders just above section $\mathrm{O}$ (h $8.2 \mathrm{~m}$ ). The branching point of the double leaders was $8.25 \mathrm{~m}$ above the ground and hachiro-sugi also had little wet area in the entire stems. On the other hand, wet areas occupied almost all of the heartwood areas at the low portions of the stems of three plus tree clones [kanra 1 (Fig. 3), numata 2, and ashigarashimo 9] and of a cultivar (kumotoshi). However, in these clones and this cultivar, the high portions of the stems tended to contain less water than the low portions.

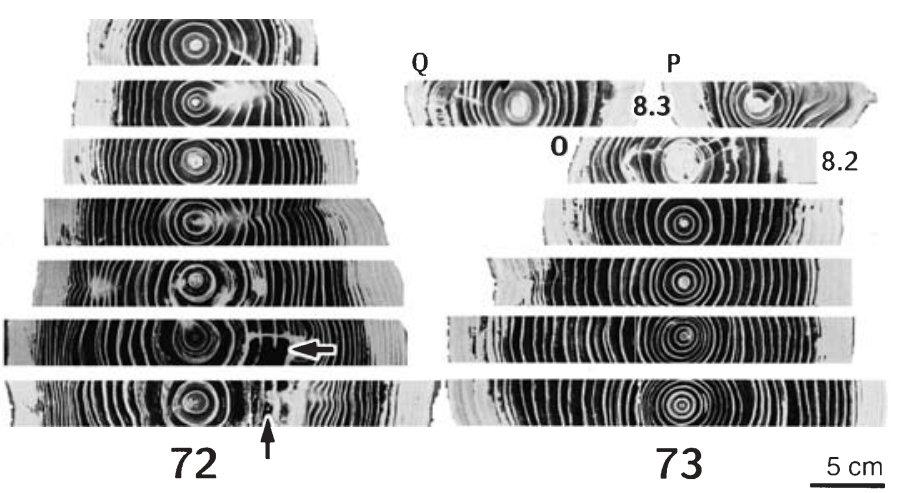

Figures 8 and 9 are sections taken serially at longitudinal intervals of $5 \mathrm{~cm}$ and $5 \mathrm{~mm}$, respectively. Figure 10 shows four serial longitudinal radial sections. As the figures show, changes in water distribution patterns were usually gradual in the longitudinal direction of the stems. Sometimes there were rapid, dramatic changes in the water distribution (e.g., arrowheads in Figs. 8 and 9) in irregularly distributed wet 

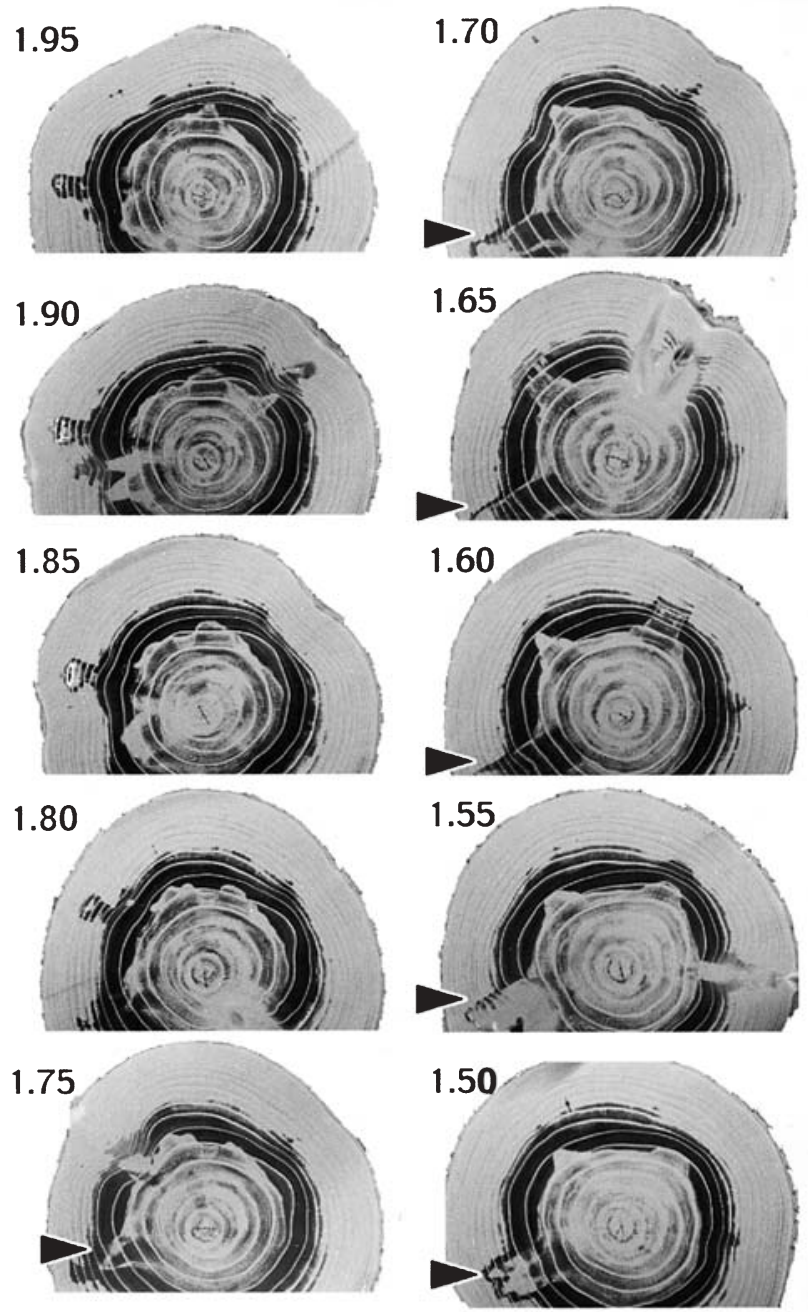

$\mathrm{CT} 2$

$5 \mathrm{~cm}$

Fig. 8. Soft X-ray photographs of sections collected serially at 5 -cm intervals from a tree, showing both gradual changes of wet area distribution in the longitudinal direction of the stem in a regularly distributed wet area and rapid changes of the wet area in the irregularly distributed wet area. Tree CT2 is a Chizu tree. Section heights 1.50$1.95 \mathrm{~m}$. Arrowheads indicate effects of an increment core boring carried out several years before harvesting the tree

areas. Wet areas connected to wounds frequently showed such rapid longitudinal changes in water distribution.

The parts of the heartwood where wet areas were observed tended to be dark (more or less black), as noted by many others. ${ }^{4,7}$ However, this description is a rough one. When a detailed comparison was made, we did not find a strict match between heartwood color and water distribution. Figure 11 shows a section in the green condition. At the point indicated by a single large arrow, a black area in Fig. 11a corresponds well with a wet area in Fig. 11b. On the other hand, an area indicated by an asterisk is not black in Fig. 11a, but there is a wet area in Fig. 11b. Another area, pointed out by double small arrows, is only slightly darker than the surrounding moderate moisture area, but it is clearly a wet area. The black area in Fig. 11a near the double arrows is also a wet area. Botan-zai, which was irregularly appearing discolored wood in $C$. japonica ${ }^{8,9}$ was
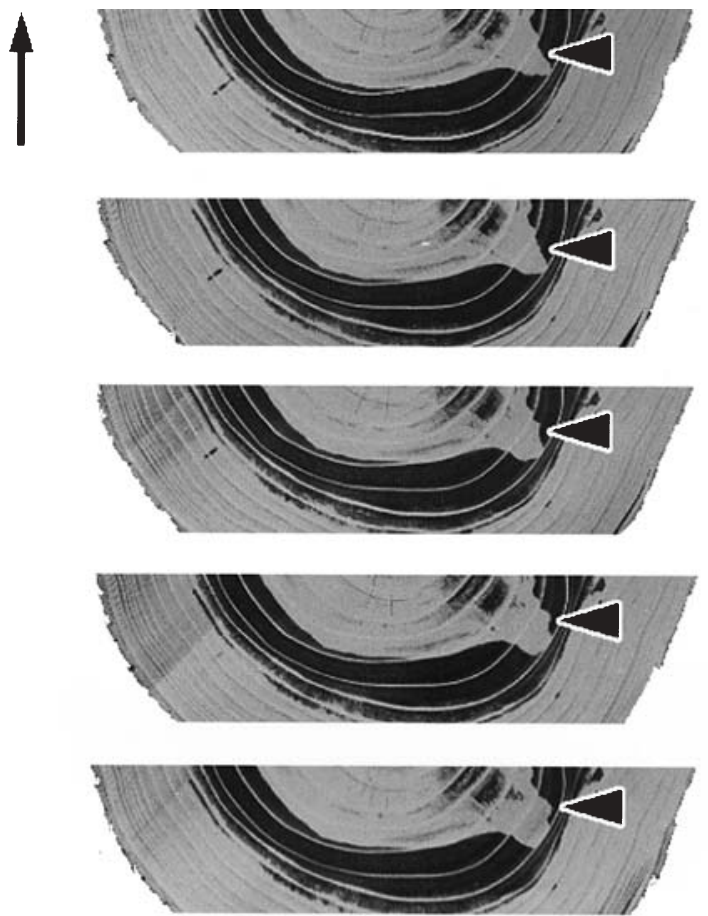

CT2

$5 \mathrm{~cm}$

Fig. 9. Soft X-ray photographs of sections collected serially at 5-mm intervals from a tree, showing both gradual and rapid changes of wet area distribution in the longitudinal direction. Tree CT2, a Chizu tree. Section height $1.25 \mathrm{~m}$. Arrowheads indicate a rapid change of water distribution in irregularly distributed wet area. Arrow indicates upward direction of the stem
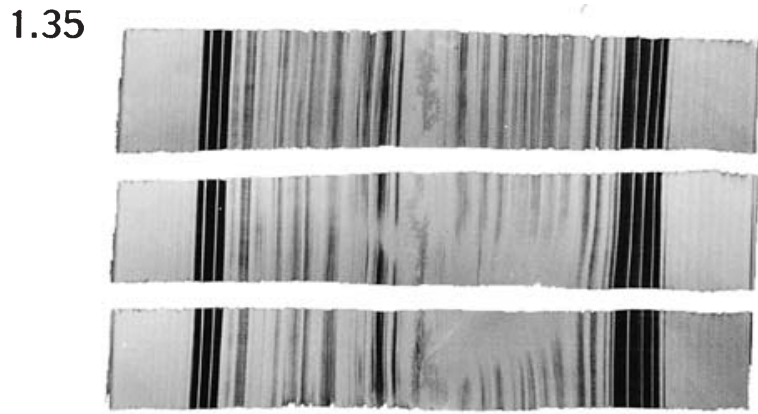

1.15
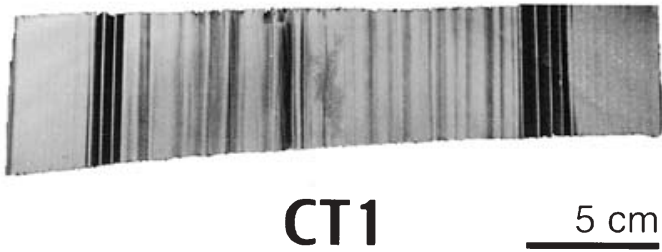

$5 \mathrm{~cm}$

Fig. 10. Soft X-ray photographs of serial radial sections collected from a tree showing gradual changes of the wet area distribution in the longitudinal direction. Tree CT1. Section heights $1.15-1.35 \mathrm{~m}$

also observed in our specimens (Fig. 12). Wet areas were observed in botan-zai, but areas of discoloration do not always match the wet area distributions. In general, wet areas were not always black as described above. However, black discolored areas indicated wet areas in most cases. 

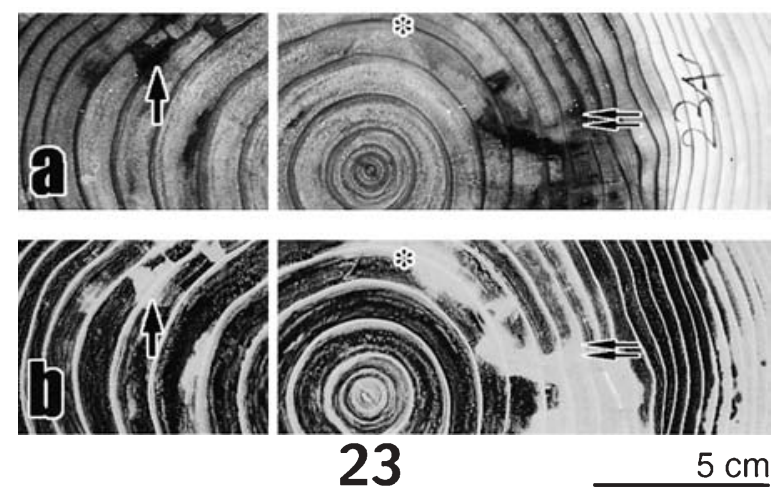

Fig. 11. Optical (a) and soft X-ray (b) photographs of a section showing matching and mismatching between discoloring and wet area distribution. Tree 23, a Mito clone, tenryu 11 . Section height $2.0 \mathrm{~m}$. Asterisks and double arrows indicate mismatches of discoloration. Single large arrows indicate a match of the two

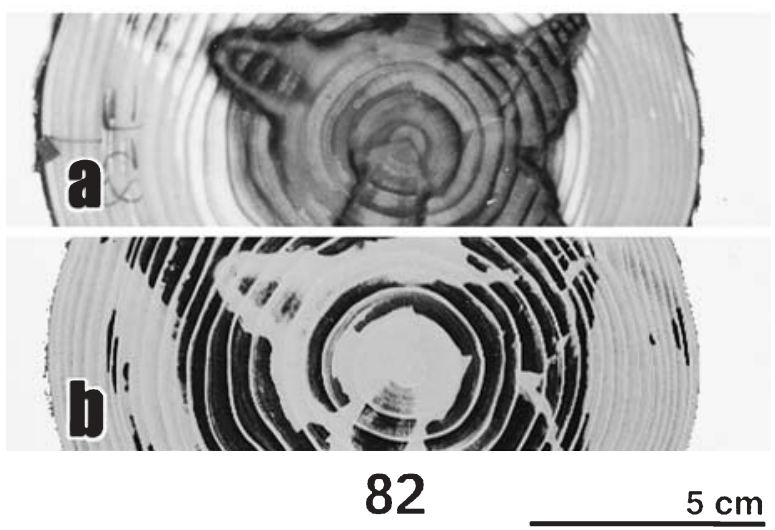

Fig. 12. Optical (a) and soft X-ray (b) photographs of a section, showing the "botan-zai" appearance and mismatches between discoloration and wet area distribution. Tree 82, a Mito clone, higashi-shirakawa 5. Section height $8.1 \mathrm{~m}$

\section{Discussion}

Our study revealed the enormous variations in water distribution in heartwood within a stem (both horizontally and longitudinally), among trees, and among genotypes. We could not identify a universal changing pattern in wet area distribution in the longitudinal direction of the stems in the heartwood of $C$. japonica. Therefore, we conclude that the changing patterns were different among individual trees. The most concise conclusion of our study is that the water distribution in the heartwood of $C$. japonica is extremely complicated. Many authors have investigated the moisture content of the heartwood of $C$. japonica, and many reports have been published..$^{1-7,10,11}$ Moreover, we have described more details about the features of wetwood in stems and about the variations and similarities among trees. Despite those efforts, the cause and mechanism of the formation and development of wetwood in C. japonica remain poorly understood. One reason for the difficulty is the complexity of the water distribution in the heartwood.
Although the variation among trees was generally enormous, the wet area distribution patterns at given heights and their longitudinal changing patterns were similar among individual trees within a clone or cultivar. Many authors ${ }^{2,610,11}$ have confirmed a strong relation between water accumulation in heartwood and the genetic origin of the trees, and it has been thought that the wetwood of C. japonica is an inherited characteristic. On the other hand, some clones and cultivars showed different wet area distribution patterns among individuals. In these cases, much irregularity was observed in wet area distributions in the stems. For example, irregularly distributed wet areas are highly developed, and little regularly distributed wet area can be seen in the trees in Fig. 6. In a sense, when only the regularly distributed area is considered, the three individuals in Fig. 6 have similar distribution patterns. By excluding irregularly distributed wet areas from the evaluation of wet area distribution patterns, seven clones or cultivars determined to be "moderate" or "large" in Table 1 (clones 8, 9, 11, 12 and cultivars E, L, V), would instead be categorized as "small," and two cultivars originally categorized as "large" (R, T) would become "moderate." Nakada et al. ${ }^{6}$ defined seven types of longitudinal change in the moisture content of heartwood. The Mito cultivars are identical to those used in the previous report. ${ }^{6}$ The sample sections described in this article were obtained immediately next to the wood blocks used for measuring moisture content in the previous report. ${ }^{6}$ The averaged moisture content of heartwood at given heights also varied along the stem axes. ${ }^{6}$ The changing patterns of moisture content and the changing patterns of the proportion of wet areas in heartwood agreed well. For example, tree $\mathrm{H} 2$ (compare Fig. 2 in this article and Fig. 3 in Nakada et al. ${ }^{6}$ ) was categorized as a typical "type (," which is the type showing high moisture at the low and high portions but low moisture in the middle portion in the longitudinal change of moisture content of heartwood. ${ }^{6}$ At $0.7 \mathrm{~m}$, a wet area distributed as type $2 / 3$ occupied half of the heartwood area, and the moisture content of heartwood was about $140 \%$. In the middle parts $(3.5,5.5$, and $7.5 \mathrm{~m})$, wet areas were observed only around the pith (type 2), and moisture content was about $80 \%$. At $11.5 \mathrm{~m}$, the proportion of wet area in the heartwood increased, and the moisture content reached about $130 \%$. Figures 5-7 and Table 1 describe the wet area distribution patterns and their variability within each clone and cultivar. The variation is enormous among clones and among cultivars. At the same time, a general similarity within each clone and each cultivar was also seen. These facts agree with those of Nakada et al., ${ }^{6}$ who found that individuals within each cultivar showed a similar longitudinal changing pattern of moisture content along the stem axis. We conclude that the longitudinal changing pattern of regularly distributed wet areas along the stem is a genetic characteristic of each clone and cultivar.

There is a theory that wetwood is a disease of wood caused by bacterial infections. ${ }^{12} \mathrm{We}$ observed in this study that some wetwood was connected to mechanical wounding (Fig. 8), injuries by insect attacks (Fig. 7), and broken branch stubs. The portions indicated by the arrowheads 
in Fig. 8 may be examples of this so-called bacterial wetwood. $^{13,14}$ The wetwood here was connected to a hole that had been bored to remove an increment core at a slightly lower position of the pictures. In such cases, bacteria could invade easily through the hole. On the other hand, reliable evidence of a bacterial origin of wetwood in some species, especially in conifers (including $C$. japonica), has not been obtained. ${ }^{15}$ Itoh $^{16}$ investigated $C$. japonica trees with black heartwood, a condition strongly related to wetwood, ${ }^{7}$ and concluded that the results for the participation of microorganism in typical black heartwood were negative. However, Itoh $^{16}$ isolated microorganisms from black heartwood surrounding wounds, such as dead knots, and concluded that microorganisms could be a cause of blackening in these cases.

To explain both our results and the association of bacteria to wetwood, we hypothesize that there are two types of wetwood in C. japonica: genetically defined wetwood and wetwood induced by secondary causes. Although both types of wetwood show similar phenomena (i.e., discoloration and water accumulation), they can be distinguished by the regularity or irregularity of the shapes of discoloration and water accumulation and by the longitudinal changing patterns of wet area distribution, whether gradual or rapid. We observed that the longitudinal changing pattern of a regularly distributed wet area was gradual and that the patterns were similar among individuals within clones or cultivars. We postulate that clones and cultivars featuring well-developed regularly distributed wet areas have genetic characteristics that let wetwood develop in their stems. On the other hand, irregularly distributed wet areas showed rapid longitudinal changes and were often connected to wounds or knots. Moreover, irregularly distributed wet areas tended to appear in the upper parts of stems, where branches were dying; that is, the conditions seemed conducive for invasion by microorganisms into the wood. Genetically defined wetwood and secondarily induced wetwood correspond to regularly distributed wet areas and irregularly distributed wet areas, respectively.

Many authors have pointed out there is a relation between black heartwood and wetwood (or heartwood with a high moisture content) in $C$. japonica. ${ }^{4,7}$ The Forestry and Forest Products Research Institute (FFPRI) and the Agriculture, Forestry and Fisheries Research Council (AFFRC) ${ }^{17}$ categorized three causes of the black heartwood condition of $C$. japonica: genetic factors, stimulation by wounding (including botan-zai), and fungal infection (by Macrophoma spp.). The FFPRI and AFFRC ${ }^{17}$ noted that irregular shapes of the discoloration characterize the latter two types. The genetic-type discoloration should correspond to the genetically defined wetwood. The woundstimulated type and the Macrophoma type would be equivalent to the secondarily induced wetwood. Mismatches between discoloration and wet area presence (e.g., in Figs. 11 and 12) were often observed in irregularly distributed wet areas, which were thought to be secondarily induced wetwood. Both discoloration and water accumulation are considerable defensive responses of trees against decay fungi. ${ }^{12,18}$ The mismatch can be explained by a hypothesis that the mechanism underlying discoloration is different from the underlying accumulation of water in heartwood. For instance, we observed discolored zones that resembled cases of Macrophoma infection in our specimens, although we did not confirm the presence of the microorganism. In the Macrophoma-type discoloration, the fungi synthesize enzyme-producing black pigments. ${ }^{17}$ In such cases discolored zones appear independently from water accumulation.

The results of this study show that one tree (tree 72) of clone godai 1 had serious decay caused by attacks of sugi bark borers (Fig. 7). Another tree (tree 73) of the same clone had double leaders. These trees seem to be in a condition conducive to invasion by microorganisms. One could predict that the trees would develop secondarily induced wetwood. In fact, wet areas were present around the decay and close to the branching of the leaders. However, the development of wetwood was limited in these trees. This contradiction can be explained if the development of secondarily induced wetwood is also genetically controlled. We postulate that the genetic abilities of trees 72 and 73 were not enough to provide mechanisms to accumulate a large amount of water. As a result, secondarily induced wetwood did not develop well. We also postulate that a function of wetwood for the tree's life is a defense mechanism against decay-causing microorganisms because accumulation of water in heartwood produces an anaerobic condition, which limits the activity of many kinds of decaycausing microorganisms. Tree 72 could not develop secondarily induced wetwood well, so decayed zones (Fig. 7) appeared around the wounds made by sugi bark borers. Therefore, we hypothesize that irregularly distributed wet areas (i.e., secondarily induced wetwood) in C. japonica are genetically controlled and formed by the trees themselves to defend against decay-causing microorganisms. ${ }^{12}$ In addition, anaerobic bacteria may be associated with wetwood development, as has been shown in other species. ${ }^{12,18}$ This hypothesis can explain both the genetic control of wetwood development and the absence ${ }^{16}$ of microorganisms in some cases.

In the present Japanese wood market, it is virtually necessary to secure the stability of lumber by drying it. The performance of kiln drying must depend on the initial moisture content of wood and its variability. With lumber drying, $C$. japonica has a large disadvantage: water accumulation in the heartwood and its variability among trees, among logs, and among individual lumber products. Therefore, genetic improvement in the moisture content of heartwood in C. japonica is strongly required. Many reports have presented the great potential of genetic improvements, ${ }^{2,6,10,11}$ and this article supports that.

The current breeding program in Japan operates according to a scheme in which the clonal characteristics of plus trees are evaluated. In this scheme the evaluation of clonal characteristics must be reliable. The heartwood water accumulation in clones of $C$. japonica plus trees can be evaluated by observing the wet area distribution patterns. For evaluating clones, soft X-ray photography is more effective than the oven-drying method of determining the mean moisture 
content of heartwood because the former can detect wet area maldistribution but the latter cannot. ${ }^{2}$ Using the twodimensional wet area distribution patterns, we succeeded in evaluating the wet area distribution in stems of trees not only at each horizontal plane but also three-dimensionally, as shown in this article. Soft X-ray photography is highly useful for clonal evaluation of the Japanese breeding program for C. japonica.

Lumber drying is made difficult by moisture variations within logs, which undoubtedly are due to variations in the wet area distribution within logs. The longitudinal changing patterns of wet areas were sometimes dramatic throughout the length of the stem (e.g., tree 11 in Fig. 6). Table 1 represents the wet area distribution patterns in each tree and the longitudinal changing pattern of the proportion of wet area in the heartwood from a low portion $(0.7-1.2 \mathrm{~m}$ above ground, depending on the tree) to a middle portion (about $4 \mathrm{~m}$ above ground). This range of heights in stems is nearly equivalent to the length between the bottom and top of a 4-m butt log, which is the common size in the Japanese wood market for $C$. japonica. (At the same time, the butt $\log$ is the most valuable part of the whole tree and therefore is necessary to consider.) In longitudinal changing patterns within the 4-m range in lower stems, half of the investigated trees show "type l" (more wet area in the low portions and less wet area in the middle portions; the proportion of wet area in the heartwood falls as the height increases). The second abundant pattern was "type l" (wet area proportion in the heartwood being stable and not changing along the stem axes). The percentages of type $\backslash$ and type $I$ in all pattern-evaluated trees were $47 \%$ and $43 \%$, respectively. Table 1 indicates that trees showing type 1 in the horizontal wet area distribution at low portions in the stems tend to be type I in longitudinal changing pattern within the range of a 4-m butt log. If such clones were selected for breeding materials, the selected population would include a small wet area (i.e., low moisture content of the heartwood) in butt logs. However, no indication about higher portions, such as $10 \mathrm{~m}$ above the ground, was given by the low portion of the wet area distribution (Figs. 2-7).

At the same time that genetic selection is undertaken practically in the breeding program, an understanding of the mechanism by which wetwood develops in $C$. japonica is expected. We report results from trees that are about 30 years old, but the rotation age of $C$. japonica in Japanese forestry ranges from 40 to 60 years. At present, no one can predict a wet area distribution 20 years from now. Knowledge about the wetwood mechanism is expected to make such a prediction possible. One promising approach to understanding wetwood is to investigate materials that have an identical genetic origin and that are planted in various conditions (i.e., individuals within a clone planted in many test stands). Soft X-ray photography was shown here to be a suitable method for studying environmental effects on wet area distribution in the stems.

\section{References}

1. Nakada R, Fujisawa Y, Hirakawa Y (1999) Soft X-ray observation of water distribution in the stem of Cryptomeria japonica D. Don. I. General description of water distribution. J Wood Sci 45:188-193

2. Nakada R, Fujisawa Y, Hirakawa Y (1999) Soft X-ray observation of water distribution in the stem of Cryptomeria japonica D. Don. II. Types found in wet area distribution patterns in transverse sections of the stem. J Wood Sci 45:194-199

3. Kamei J, Tsushima S (1988) Moisture distribution of standing sugi (Cryptomeria japonica) trees (in Japanese). Nihon Ringakkai Kyushu-shibu Kenkyu Ronbun Shu 41:221-222

4. Matsumura J, Oda K, Morikawa T, Tsutsumi J (1994) Variation of green moisture content and lightness in longitudinal and radial direction of sugi heartwood (in Japanese). Nihon Ringakkai Kyushu-shibu Kenkyu Ronbun Shu 47:243-244

5. Miwa Y (1985) Sugi no namazai gansuiritsu bunpu ni tuite [On the distribution of green moisture content within stems of Cryptomeria japonica] (in Japanese). In: Abstracts of 35th annual meeting of Japan Wood Research Society, p 31

6. Nakada R, Fujisawa Y, Hirakawa Y, Yamashita K (1998) Longitudinal change of the green moisture content in the stem of Cryptomeria japonica D. Don (in Japanese). Mokuzai Gakkaishi 44:395-402

7. Kawazumi K, Oda K, Tsutsumi J (1991) Heartwood properties of sugi (Cryptomeria japonica): moisture content of green wood, hot water extractives and lightness (in Japanese). Bull Kyushu Univ For 64:29-39

8. Ohsako Y, Tsutsumi T, Nobuchi T, Morita M (1972) Studies on the forest management from the viewpoint of wood quality (1) on BOTAN-wood (in Japanese). Bull Kyoto Univ For 44:159175

9. Ohsako Y, Tsutsumi T, Nobuchi T, Morita M (1974) Studies on the forest management from the viewpoint of wood quality (2) development of Botan in connection with pruning (in Japanese). Bull Kyoto Univ For 46:103-114

10. Fujisawa Y, Ohta S, Nishimura K, Toda T, Tajima M (1995) Variation in moisture contents of heartwood among clones and test stands in sugi (Cryptomeria japonica) (in Japanese). Mokuzai Gakkaishi 41:249-255

11. Kawamura T, Mikami S (1987) Sugi ni okeru shinzai gansuiritsu no kuron kan heni [Clonal variation of heartwood moisture content in Cryptomeria japonica] (in Japanese). Trans Meeting Tohoku Br Jpn For Soc 39:72-73

12. Shigo AL (1986) A new tree biology. Shigo and Trees Associates, Durham, NH

13. Partridge JE (1998) Bacterial wetwood. 〈http://plantpath.unl. edu/peartree/homer/disease.skp/Hort/Trees/BacWetWood.html $\rangle$ Accessed September 14, 2001

14. Murdoch CW (1992) Detection system to identify wetwood in standing living trees and in cut logs and boards. 〈http:// www.nal.usda.gov/ttic/industry/hrdwood1.htm $\rangle$ Accessed September 14, 2001

15. Panshin AJ, de Zeeuw C (1980) Textbook of wood technology, 4th edn. McGraw-Hill, New York

16. Itoh S (1996) Kokushinzai no hasseini kanyosuru kinrui [Microorganisms associated with occurence of black-heart] (in Japanese). Shohou FFPRI 94:4-5

17. FFPRI and AFFRC (Forestry and Forest Products Research Institute and Agriculture, Forestry and Fisheries Research Council, Ministry of Agriculture, Forestry and Fisheries) (1995) Sugi kurojin, sono hassei to taisaku [Black-heart in Cryptomeria japonica, its occurrnce and dealings for it] (in Japanese). FFPRI and AFFRC

18. Hartley C, Davidson RW, Crandall BS (1961) Wetwood, bacteria, and increased $\mathrm{pH}$ in trees. Forest Products Laboratory Report 2215. Forest Products Laboratory, USDA Forest Service, Madison, WI 